\title{
The Pericarditis in CHU of Point G and Luxembourg: Clinical Aspects and Etiologies
}

\author{
Mamadou Diakité1, Abdoulaye Kanté2*, Bréhima Coulibaly², Mamadou Almamy Keita², \\ Drissa Traoré2, Bréhima Bengaly², Siaka Diallo², Mariam Daou33, Babou Bah², \\ MoustaphIssa Magané4, Tata Touré ${ }^{2}$, Bakary Keita ${ }^{4}$, Birama Togola², Drissa Ouattara ${ }^{2}$, \\ Souleymane Sanogo ${ }^{2}$, Timbely Guidèrè2, Nouhoum Ongoïba ${ }^{2}$
}

\author{
${ }^{1}$ Department of Cardiology, CHU Point G, Bamako, Mali \\ ${ }^{2}$ General Surgery Department, CHU Point G, Bamako, Mali \\ ${ }^{3}$ Department of Neurology, Gabriel Touré Teaching Hospital, Bamako, Mali \\ ${ }^{4}$ Anesthesia Service and Resuscitation Department, CHU Gabriel Touré, Bamako, Mali \\ Email: *kanteim@yahoo.fr
}

How to cite this paper: Diakité, M., Kanté, A., Coulibaly, B., Keita, M.A., Traoré, D., Bengaly, B., Diallo, S., Daou, M., Bah, B., Magané, M., Touré, T., Keita, B., Togola, B., Ouattara, D., Sanogo, S., Guidèrè, T. and Ongoïba, N. (2018) The Pericarditis in CHU of Point G and Luxembourg: Clinical Aspects and Etiologies. Open Journal of Thoracic Surgery, 8, 68-73. https://doi.org/10.4236/ojts.2018.84012

Received: October 12, 2018

Accepted: November 20, 2018

Published: November 23, 2018

Copyright ( $\odot 2018$ by authors and Scientific Research Publishing Inc. This work is licensed under the Creative Commons Attribution International License (CC BY 4.0).

http://creativecommons.org/licenses/by/4.0/

\begin{abstract}
The authors bring back 70 cases of pericarditis brought together between 2012 and 2017 in the service of surgery B of the CHU Point G and to the Hospital Mother-Child, the Luxembourg in Mali. The average age of the patients is 31.5 years with extremes of 2 years and 84 years. The tubercular etiology widely comes to mind with 49 cases. The diagnostic contributions of the echocardiography are analyzed. The accent is put on good tolerance hemodynamic of the tubercular pericarditis. The forecast depends essentially on the etiology and on the diagnostic delay; indeed the tamponade pericardium can be inaugural or complicated; the evolution of the pericarditis is burdened of a heavy mortality ( $4.2 \%$ in our series). On the other hand the passage in the chronicity complicates essentially pericarditis seen late (8.6\% in our series).
\end{abstract}

\section{Keywords}

Etiology of the Pericarditis, Aspect Private Hospital, CHU G-Spot and Luxembourg

\section{Introduction}

The tuberculosis always constitutes a problem of public health in particular in our countries in the South of Sahara with the coinfection of the HIV [1]. Its lung localization remains by far the most frequent. However in particular serous extra lung infringements are possible. It is most of the time about tubercular pericar- 
ditis which can be at the origin of mortal complications [2] [3]. She can arise at any age but affects especially the young subject. The objective of this study was to specify the clinical particularities and the aspects etiologies pericarditis infringements in the service of surgery B of the University Hospital of the Point G in Mali.

\section{Materials and Methods}

We realized a forward-looking and retrospective study from January, 2012 till December, 2017 in the service of surgery B to the University Hospital of the Point G of Bamako. All the patients were included to whom the histological examination confirmed the diagnosis of tuberculosis by the highlighting of a granulomatous pericardium inflammation. The patients to the diagnosis of tubercular pericarditis were included in this study was confirmed by the various takings. An examination of spits in search of bacilli acido-alcoho Resistance fighters (BAAR) was realized at all the patients presenting a chronic cough with expectorations.

A complete clinical examination, a cardiac ultrasound, and ECG were made at all the patients.

The studied parameters were the following ones:

- the sociodemographic data,

- the clinical signs and para clinics.

\section{Results}

Between January, 2012 and May, 2017, we brought together 70 cases of pericarditis left in 40 men and 30 women. The average age of the patients is of 31.5 years with extremes of 2 years and 84 years. $80 \%$ of our sick arise from disadvantaged socioeconomic circles.

\subsection{The Clinical Demonstrations (Table 1)}

In our series, the clinical signs differed according to the etiology of the pericarditis. The septic pericarditis is characterized by a change of the general state. During the tubercular pericarditis, the picture is sometimes insidious and latent. The dyspnea is present in every case in variable degrees. The thoracic pains are moderated most of the time, deaf, found in 40 cases, they are intense feigning angina pains at 15 patients, they are lacking at 15 patients. The friction pericardium pathognomonic the affection is found at 47 patients.

\subsection{The Electrocardiography}

The ECG Realized at all the patients objectified the micrvoltage, the desorders of the repolarization and the palpitation sinusale (Figure 1).

The radiography of the thorax: we noted to the radiography diverse signs (Table 2). 
Table 1. The main clinical signs.

\begin{tabular}{ccc}
\hline Main clinical signs & Number & Percentage \\
\hline Dyspnea & 70 & $100 \%$ \\
Thoracic Pain & 55 & $78.6 \%$ \\
Fever & 5 & $7.1 \%$ \\
Tamponade & 8 & $11.4 \%$ \\
Friction Pericardium & 31 & $44.2 \%$ \\
\hline
\end{tabular}

Table 2. Radiological data.

\begin{tabular}{ccc}
\hline Data of the radiography of the thorax & Number & Percentage \\
\hline Cardiomegaly & 54 & $77.1 \%$ \\
Image in decanter & 42 & $60 \%$ \\
Image in double (copy) shadows cardiac & 5 & $7.1 \%$ \\
Effusion associated pleural & 7 & $10 \%$ \\
\hline
\end{tabular}

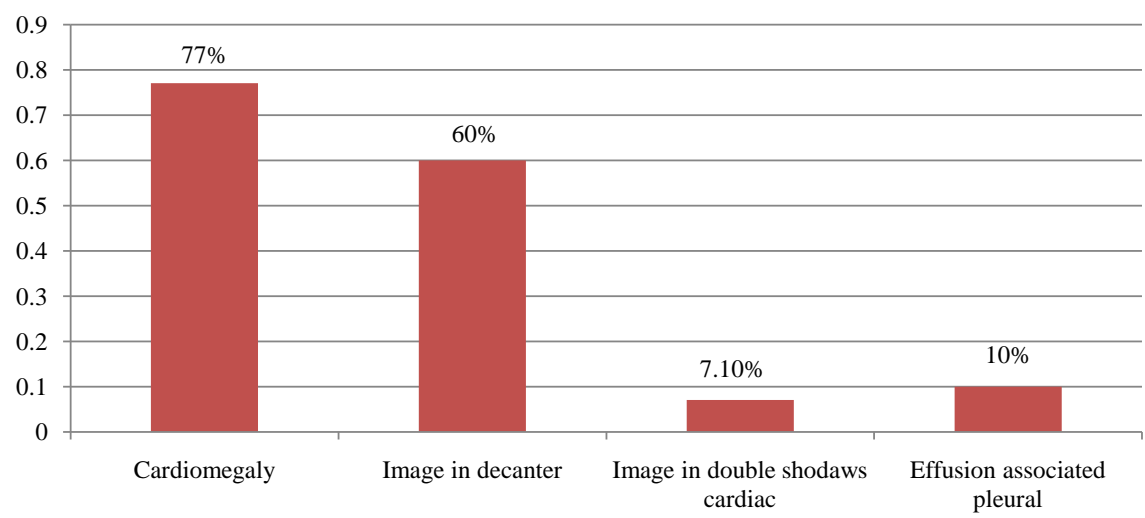

Figure 1. Electric data.

\subsection{The Echocardiography}

We found in the cardiac ultrasound realized at all the patients:

- an effusion pericardium of low abundance in $7.1 \%$, average abundance in $34.3 \%$ and big abundance in 50\% with signs of compression of the right cavities;

- signs of constriction in $8.6 \%$ (pericardium dry).

\subsection{The Biological Examinations}

We noted an inflammatory syndrome to $67.1 \%$ of our sick. Besides we asked for other biological examinations according to the clinical state of the patients.

\subsection{The Histological Examination}

The tissue pericardium was obtained by surgical drainage by xiphoïdienne way in $91.4 \%$ and during the decortication pericardium by sternotomie median in $8.6 \%$. The tuberculosis represents the main cause of infringement pericardium, it 
is found at 49 sick that is $70 \%$ of the cases. Other etiologies were not specific and metastatic (Table 3).

\subsection{The Evolution}

The short-term evolution is favorable to $90 \%$ sick. We recorded 3 deaths (4.3\%) among which 2 cases arose at HIV-positive patients. The rate of morbidity was $5.7 \%$. It was three second offenses and an infection of the operating site.

\section{Discussion}

The acute and chronic pericarditis is frequent, they arise at any age with however a preference at the young adult [1] [2] [3].

So in our study $67.1 \%$ of the sick were less than 40 -year-old. A male ascendancy often described in the literature was Noticed at our patients [4] [5] [6].

The clinical demonstrations in our study are rather comparable to those of the literature.

The change of the general state and the painful dyspnea dominate the board of the acute pericarditis, while for the subacute and chronic pericarditis, it is most of the time about a progressive installation of dyspnea and about edema of lower limbs [7] [8] [9].

The pericardium friction is not constantly found. Indeed as in numerous studies, we observed it at $44.2 \%$ of our patients [7] [9].

The electrocardiogram often allows evoking the diagnosis. The signs most frequently observed are the microvoltage and the disorders of the repolarization. The radiography of the thorax objectifies an increase of the cardiac volume [5] [10]. In our series, these signs were noted at the majority of our patients.

The echocardiography revolutionized the diagnosis of the effusions pericardium [2] [9] [10].

Indeed she allows appreciating the abundance of the effusion, to reveal the signs of compression of the right cavities and to look for signs of constriction pericardium. Besides, she allows adding suggestions etiologies which remain the main problem. Indeed, if in the developed countries we attend a decline of the tuberculosis which represents only $12 \%$ of infringements pericardium [11] [12]. In Mali as in most of the developing countries, the tubercular pericarditis occupies the first row [13].

Table 3. Result anatomopathologic of the biopsy pericardium showing the various etiologies.

\begin{tabular}{ccc}
\hline Results & Number & Percentage \\
\hline Tuberculosis & 49 & $70 \%$ \\
Not specific acute Pericarditis & 13 & $18.6 \%$ \\
Fibrous Pericarditis & 5 & $7.1 \%$ \\
Metastases pericardium of cancer & 3 & $4.3 \%$ \\
Total & 70 & $100 \%$
\end{tabular}


The diagnosis of the tubercular pericarditis is held on a set of épidémio-clinical, biological arguments and echocardiographic.

However in the absence of a histological confirmation difficult to obtain at most of the patients, the good evolution under antituberculous treatment adds an argument in favor of a tubercular pericarditis. The acute idiopathic pericarditis viral occupies the 2 nd rank; of mild evolution they are of a symptomatic treatment.

The primitive neoplastic pericarditis is exceptional [14].

The secondary neoplastic localizations are more frequent bound in $80 \%$ of the cases to a cancer of breast or the lung, to leukemia or to a lymphoma not hodgkinien. They are burdened by a heavy mortality.

If the short-term evolution is generally favorable except the acute accidents, the problem remains that of the constriction pericardium which complicates gladly the tubercular pericarditis.

\section{Conclusion}

The clinical approach to a patient reached of a pericarditis comes up against of multiple difficulties because of big diversity etiologies. The pericardium biopsy constitutes a contribution mattering in the etiologic diagnosis of the pericarditis. The tubercular etiology remains frequent in our country.

\section{Conflicts of Interest}

We, authors of this article declare that there is no conflict of interests

\section{References}

[1] Agrhaly, et al. (1984) The Tubercular Pericarditis in Bamako. Tropical Cardiology, 4, 17-24.

[2] Harmang, A.J. (1975) Chronic Pericarditis. EMC, Paris.

[3] Behegt (1977) The Pericardic Affections in Zaire. Tropical Cardiology, No. 3, 147-151.

[4] Boubel, K., et al. (1999) Pericarditis: Clinical Approach and Aspects Etiologic. Magazine Medical, No. 335, 8-10.

[5] Bouchtiv, M. (1987) Contribution to the Study of the Acute Pericarditis. The Thesis of Medicine Rabat, 126.

[6] Fourcade, J.P. (1975) Acute and Subacute Pericarditis Observed in a Cardiology Department. Medical journal of Bordeaux, No. 8, 95-101.

[7] Nataf, J., et al. (1994) Pericarditis Constrictive Chronicles. Retrospective Study of 84 Sick. Archives of the Heart Diseases, No. 87, 241-245.

[8] Quere, J.P., et al. (1996) Pericarditis Constrictive Chronicles about 3 Cases Revealed by a Refractory Cardiac Insufficiency. 89, 1651-1658.

[9] Laurent, F., et al. (1981) The Echocardiography in the Balance Sheet of Pericarditis. Archives of the Heart Diseases, No. 85, 85-92.

[10] Admi, M. (1989) Contribution of Echocardiography in the Tubercular Acute and Subacute Pericarditis. Thesis of Medicine Casa, 337. 
[11] Agner, R.C., et al. (1979) Pericardits Differential Diagnosis Considérations. Archive International of Medicine, No. 139, 231-234.

[12] Chaix, A.F., et al. (1985) Current Aspects of Tubercular Pericarditis. African Journal of Cardiology, No. 14, 67-71.

[13] Bertrand, E., et al. (1968) Study of 62 Cases of Acute Pericarditis. Medical Africa, 7, 812-820.

[14] Loire, R., et al. (1993) Neoplastic Pericarditis: Study by Thoracotomy and in 80 Cases. Vol. 22, Medical Press, 244-248. 